\title{
Multiculturalismo y pueblos indígenas en zonas urbanas en Canadá: una reflexión sobre el debate entre el reconocimiento y la redistribución
}

\author{
Ruth A. Dávila Figuero* *
}

\section{RESUMEN}

Uno de los retos que enfrentan las políticas multiculturales es el crecimiento de la población indígena en centros urbanos. A partir del caso de las mujeres, en este artículo se intenta señalar que las políticas multiculturales basadas en el reconocimiento no son adecuadas para solucionar las condiciones de vida en zonas urbanas. Se discute el multiculturalismo centrado en el reconocimiento y enfocado en la ciudadanía diferenciada, así como el acomodo de la diversidad y la redistribución que pondera las diferencias de orden estructural y la intersección entre la raza, la clase y el género.

Palabras clave: Canadá, multiculturalismo, pueblos aborígenes, reconocimiento y redistribución.

\section{Abstract}

One of the challenges facing multicultural policies is the growth of the indigenous population in urban areas. Using the case of women, this article attempts to point out that that multicultural policies based on recognition are not adequate for resolving living conditions in urban areas. It discusses multiculturalism centered on recognition and focused on differentiated citizenship, as well as an understanding of diversity and redistribution that ponders structural differences and the intersection of race, class, and gender.

Key words: Canada, multiculturalism, aboriginal peoples, recognition and redistribution.

\footnotetext{
* Becaria del Programa de Becas Posdoctorales de la Universidad Nacional Autónoma de México, Centro de Investigaciones sobre América del Norte, uNAM. ra_davila@yahoo.com.
} 


\section{INTRODUCCIÓN}

Canadá es un país multicultural por definición. Se caracteriza por su diversidad cultural, étnica, religiosa y lingüística; ${ }^{1}$ es un Estado poliétnico y multinacional. Su condición poliétnica está determinada por la diversidad de minorías resultado de las migraciones, y su condición multinacional, por el hecho de que se funda sobre dos naciones, la británica y la francesa, además de los pueblos indígenas que, de acuerdo con la Constitución de 1982, son las Primeras Naciones (First Nations), métis e inuit.

Las Primeras Naciones son los pueblos de Canadá que tienen o no estatus indígena. Muchas usan el término Primeras Naciones o el nombre de su comunidad. Se identifican seiscientas diecisiete que representan más de cincuenta naciones o grupos culturales y cincuenta lenguas indígenas. Los métis son las personas descendientes de los matrimonios entre indígenas y los migrantes europeos del siglo xvII y los inuit son los habitantes del norte de Canadá, a quienes se conoce de manera despectiva como esquimales, pero cuyo nombre correcto es inuit (AANDC, 2013; AFN). En 1985, Canadá publicó la Canadian Multiculturalism Act, en la cual se reconoció oficialmente como un país multicultural.

Veinticinco años después, en 2010, se editó The Current State of Multiculturalism in Canada and Research Themes on Canadian Multiculturalism 2008-2010, cuyo objetivo fue presentar el estado del multiculturalismo en Canadá y las áreas sobre las que se podría investigar para proponer mejoras en las políticas multiculturales del Estado. Entre los temas respecto a los cuales se sugiere trabajar, se encuentra el multiculturalismo y su relación con los pueblos indígenas; específicamente, se habla de "indagar sobre la relación del multiculturalismo y los indígenas en zonas urbanas" (Kymlicka, 2010: 20).

Will Kymlicka establece en dicho informe, entre otros temas, que se debe investigar/trabajar sobre los pueblos indígenas y su relación con el multiculturalismo en cuanto a dos asuntos en particular:

a) En el medio urbano, los inmigrantes y los pueblos indígenas viven cada vez más próximos. Aunque constitucionalmente están regulados por diferentes leyes y reglamentos, la realidad es que a menudo comparten los servicios públicos y el espacio público. Por lo tanto, se necesita más investigación sobre cómo las políticas del multiculturalismo, que inicialmente se pensaron para

\footnotetext{
${ }^{1}$ En 2011, el 20.6 por ciento de la población total de Canadá había nacido en el extranjero; esta proporción es la más alta entre los países miembros del G-8. En los censos de 2011, se reportaron más de doscientos orígenes étnicos distintos. Véase Statistics Canada, 2013b.
} 
los grupos étnicos de origen extranjero y minorías visibles, se pueden adaptar para satisfacer las necesidades de los pueblos aborígenes en zonas urbanas, y b) en el Norte, a veces se da la situación contraria: hay programas bien establecidos para los pueblos indígenas, incluidos los derechos de autogobierno, pero hay relativamente pocos programas de multiculturalismo para las minorías religiosas y visibles. En este contexto, los líderes indígenas a veces han visto con recelo la promoción del multiculturalismo al señalar que es una forma de diluir sus derechos duramente obtenidos (Kymlicka, 2010: 30).

Así, uno de los retos de las políticas multiculturales en Canadá tiene que ver con el constante crecimiento de la población indígena en zonas urbanas. Este reto radica, según el informe, en que las políticas multiculturales están diseñadas para dar acomodo y reconocimiento a las minorías migrantes, étnicas, y los pueblos están sujetos a otro tipo de legislación, de orden federal. Pero, dado el crecimiento de población indígena en zonas urbanas, donde comparten el espacio público con las minorías visibles y las minorías inmigrantes, las normas por las cuales se rige aquella población entran en conflicto con las políticas multiculturales. En general, los pueblos indígenas en Canadá han enfrentado, y enfrentan, condiciones de vida asociadas al orden estructural y no sólo al reconocimiento de su identidad cultural diferenciada. Retomando como ejemplo el caso de los pueblos indígenas en zonas urbanas, y en particular la situación de las mujeres indígenas, se busca demostrar que no basta con el reconocimiento y la ubicación de su identidad diferenciada, eje de las políticas multiculturales, para dar solución a los problemas que tienen actualmente los pueblos indígenas en Canadá. En ese sentido, las tesis de Nancy Fraser (2000; 2003), quien desarrolla las nociones de bidimensionalidad e interseccionalidad resaltando que la injusticia social no sólo se da en el campo del reconocimiento, sino también en el de la distribución y quien pondera la categoría de la subordinación política, económica, social y cultural, nos permiten no sólo explicar el problema, sino proponer soluciones.

Para desarrollar esta idea, el presente artículo se divide en tres partes. En el primer apartado expongo las tesis centrales de Will Kymlicka sobre su teoría liberal de los derechos de las minorías, que se centra en el reconocimiento de la identidad cultural diferenciada. En un segundo apartado, presento los planteamientos de Nancy Fraser sobre la bidimensionalidad y la interseccionalidad. En un tercero, hago una descripción de las condiciones de vida de los pueblos indígenas en zonas urbanas, destacando el caso de las mujeres, para demostrar que el problema de estos pueblos va más allá del reconocimiento de derechos diferenciados y que el tratamiento hacia ellos como minorías visibles no resolverá sus condiciones de vida, las cuales están asociadas a cuestiones de orden estructural que se enraízan en el pasado colonial. 


\section{APUNTES SOBRE El MULTICULTURALISMO: LOS DERECHOS DE LAS MINORÍAS CULTURALES Y EL RECONOCIMIENTO DE LA IDENTIDAD DIFERENCIADA}

En este subtítulo tenemos por lo menos tres ideas generales: el multiculturalismo, los derechos de las minorías culturales y el reconocimiento de la identidad diferenciada. Empecemos por definir cuáles son esas minorías culturales a las que se pretende dar un reconocimiento de su identidad diferenciada, y cuáles son los derechos que se busca no sólo reconocer, sino proteger.

Desde finales de los años ochenta del siglo xx se inicia una ola de conflictos en los que subyace la identidad. Kymlicka señala que hay dinámicas sociales poderosas en el mundo moderno que estimulan este tipo de movilizaciones. Enuncia tres factores que han hecho posible tales tendencias y que incluso son hechos inevitables en las democracias occidentales:

a) Demografía. En el pasado, muchos gobiernos tenían la previsión de que las minorías simplemente desaparecerían. Sin embargo, los pueblos indígenas son el segmento que más rápido crece de toda la población de los países en donde se encuentran, con tasas de nacimiento muy altas.

b) Conciencia de derechos. La revolución de los derechos humanos, y con ello, el desarrollo de una conciencia de derechos.

c) Democracia. La consolidación de la democracia limita la habilidad de las élites para aplastar movimientos de protesta y disidentes (Kymlicka, 2003: 104-105).

En este contexto, surgen las primeras aproximaciones teóricas al multiculturalismo y a las políticas de reconocimiento y acomodo de la diferencia y los derechos de las minorías culturales. Kymlicka (1996; 2003) señala que dentro de la diversidad cultural podemos identificar a 1) las minorías nacionales, 2) los pueblos indígenas, 3) las minorías étnicas y 4) los metecos. Explica que las minorías nacionales son comunidades extensas que se identifican a sí mismas como diferentes a la nación dominante y que han sido adheridas a una comunidad nacional más amplia por medio de conquistas, y se sienten ligadas a un territorio por razones históricas y de identidad; en este caso tenemos a los vascos, los catalanes, los corsos, los kurdos, etc. que tienen demandas nacionalistas de autogobierno y hasta de independencia o secesión.

Los pueblos indígenas ocupaban territorios que fueron colonizados; también sienten un lazo con la tierra y demandan autogobierno y autonomía. Las minorías étnicas son producto de las migraciones y son comunidades que, sin perder su iden- 
tidad cultural y sus lazos con sus lugares de origen, por decisión propia, señala Kymlicka, buscan integrarse a una comunidad más amplia, la de recepción, es decir, la de los países a los que emigran. Por último, sobre los que no abunda, pero sí los menciona, están los llamados metecos que también son migrantes, pero que no tienen un estatus oficial o residencia legal, menos aún ciudadanía, es decir, no tienen derechos ni permiso para estar en el país al cual migraron.

Los tipos de derechos que demandan estos grupos, nos dice Kymlicka (2004), son similares y graduales. También señala que estos reclamos implican la redistribución de recursos económicos y de poder político. Así, tenemos que las minorías nacionales demandan representación, autogobierno, autonomía política y en casos extremos la secesión. Sus reclamos se pueden sintetizar en dos grandes rubros: la redistribución de poderes y las políticas lingüísticas. Los pueblos indígenas reclaman derechos de autogobierno, estatus de lengua oficial, derecho consuetudinario, reclamos de tierras. Por último, las minorías étnicas sólo tienen reclamos de ciudadanía.

Las tesis centrales de los postulados teórico-filosóficos del multiculturalismo se enfocan en fundamentar los derechos de las minorías nacionales, indígenas y étnicas (migrantes). Se parte del supuesto de que la teoría liberal sobre los derechos humanos tuvo como eje a los individuos, dando por sentado que así se protegían también los derechos de las minorías. Se destaca la necesidad de un corpus de derechos que se centren en el respeto a la diferencia, en el reconocimiento y acomodo de esa diferencia que, en términos generales, es de orden cultural y está enfocada, sobre todo, en la lengua y en la identidad etnocultural.

En ese sentido,

el multiculturalismo promueve la diversidad cultural y se considera una condición para asegurar un trato igualitario a todas las comunidades en el ámbito político. Su especificidad es que enlaza derechos diferenciados de los grupos con un tratamiento igualitario de ciudadanía y establece derechos especiales a las minorías para promover su cultura. Este programa de sostenimiento de las culturas minoritarias es reforzado, por un lado, por el valor que supone la diversidad de culturas en una sociedad, y por el otro, la creencia de que los individuos valoran pertenecer a su comunidad. Ésta es una doble lectura del valor de la identidad de la comunidad y de la diversidad cultural que sostiene la necesidad de proteger y preservar a las minorías culturales (Mahajan, 2002: 146).

Pareciera que el multiculturalismo como fundamento teórico-filosófico de los derechos de las minorías, del reconocimiento de la identidad diferenciada y del acomodo de estas comunidades en el ámbito público está enfocado, sobre todo, a las así llamadas minorías étnicas (producto de las migraciones). Se vuelve problemático 
dar cauce a las demandas de las minorías nacionales y de los pueblos indígenas, cuyos reclamos se centran en el autogobierno y, en casos extremos, piden la secesión.

Los debates y posturas teóricas e ideológicas sobre el multiculturalismo centrado en el acomodo y reconocimiento de la diversidad etnocultural no estuvieron exentos de críticas. Algunas de éstas han señalado que: 1) las teorías multiculturalistas no explican los procesos de minorización de las así llamadas minorías; dichas teorías se presentan como ahistóricas, como si las minorías siempre hubieran estado ahí y no fueran cambiantes y parte de un proceso histórico más amplio y complejo; 2) desde el debate feminista, por ejemplo, se apunta que la visión multiculturalista sólo se centra en las culturas minoritarias, sin dar cuenta de que dentro de éstas también hay minorías de género, es decir, que también esas culturas minoritarias son patriarcales; 3) la visión multiculturalista sobre los derechos de las minorías no da cuenta de las relaciones de dominación y subordinación a las que, generalmente, subyace un entrecruzamiento entre clase, género y raza. Así, el origen de las diferencias y de los conflictos en la sociedad contemporánea se reduce sólo a la diferencia cultural, obviando las diferencias económicas y políticas; 4) este último punto se conecta con el anterior y tiene que ver con lo que Zizek (2007) denomina "despolitización de la economía" para argumentar que el multiculturalismo es la ideología liberal de la globalización. ${ }^{2}$

Cabe destacar que las posturas feministas mantienen una relación paradójica con el multiculturalismo, pues

la mayoría apoya el concepto de ciudadanía diferenciada, pero sigue habiendo una preocupación en tanto que las mujeres pueden seguir teniendo una condición de desigualdad y subordinación aún después de que las comunidades minoritarias se hayan empoderado. [...] Las mujeres deben incluirse como mujeres. Sin embargo, para lograr esta meta, los teóricos de la diferencia consideran necesaria la deconstrucción del sistema simbólico de la sociedad y para entenderlo, primero y sobre todo, que el discurso público no es neutral, sino que está estructurado por un grupo dominante, los varones, y a través de cualidades que expresan la diferencia [...] Particularmente, se debe comprender que las culturas no son neutrales en términos de género. La mayoría de las culturas son patriarcales y refuerzan de diversas formas, y en diferentes grados, la subordinación de las mujeres (Mahajan, 2002: 123, 125, 137).

Así pues, el eje de la argumentación de estos debates y posturas teóricas sobre los derechos de las minorías se centra, sobre todo, en la noción del reconocimiento.

\footnotetext{
2 Véanse, por ejemplo, los capítulos "Feminism and Multiculturalism" y “The Limits of Multiculturalism" en Mahajan, 2002: 123-145, 146-165; Fraser, 2000: 107-120; Žižek, 1998; Díaz-Polanco, 2006; Barry, 2001.
} 
Específicamente se habla del reconocimiento de la diferencia étnica, cultural, lingüística, etc. ${ }^{3}$ Sin embargo, me parece que la postura marcadamente liberal de Kymlicka no le permite ver lo que Nancy Fraser (2000) señala es un desplazamiento de las reivindicaciones que tenían como eje la mejor distribución hacia lo que se centraba sólo en cuestiones de orden cultural o que tienen como objetivo el reconocimiento. Es en este sentido que, en este estudio, retomo la tesis de la bidimensionalidad propuesta por Fraser (2000; 2003) para argumentar que, más que políticas multiculturales, la cuestión de los pueblos indígenas en Canadá podría tratarse a partir del reconocimiento y la redistribución, pues desde esta perspectiva se pretende lograr la justicia social, más allá de la integración, y además se asume que hay problemas de orden político y económico, aparte del cultural, que deben ser tratados no sólo desde el enfoque del reconocimiento de la diferencia.

La limitación de la propuesta de Kymlicka es la presunción de que al otorgar reconocimiento y acomodo a la diferencia cultural, los problemas de orden estructural van a desaparecer. Más aún, no veo en su discusión mención alguna a las condiciones estructurales como causa de la "minorización" de, en este caso, los pueblos indígenas, o las minorías étnicas o nacionales. En su discurso argumenta sobre una "falsa neutralidad del Estado" en el orden etnocultural, pero esa falsa neutralidad no sólo se da en ese orden, sino también en el político y el económico presuponiendo, entonces, relaciones de poder o de subordinación, en el lenguaje de Fraser (2000, 2003). Es así que la propuesta de esta autora me parece más amplia y completa en el sentido de que refiere las relaciones de subordinación en los órdenes político, cultural, económico y social. Al mismo tiempo, siguiendo a Fraser podemos dar cuenta de la interseccionalidad, pues argumenta sobre el cruce entre clase, género, raza y etnia.

\section{RECONOCIMIENTO Y REDISTRIBUCIÓN: Nancy Fraser y La JUSTICIA SOCIAL}

Fraser (2000) inicia su argumento señalando que, tras los diversos conflictos en las décadas de los años setenta y ochenta que tuvieron como eje la cuestión del reconocimiento de la identidad, la diversidad y la diferencia cultural, era preciso preguntarse si había un declive de los reclamos en torno a la distribución igualitaria. Así,

\footnotetext{
${ }^{3}$ Los pensadores más destacados que han tratado la cuestión del reconocimiento y el multiculturalismo en general son James Tully (1995), Bhikhu Parekh (2002), Chandran Kukhathas (2003), Axel Honneth (1997), y Charles Taylor (1993). Uno de los defensores más destacados de la teoría liberal de los derechos de las minorías, del reconocimiento y acomodo de la diferencia y de los derechos diferenciados es Will Kymlicka (1996; 2003; 2004; 2007). Sus obras más reconocidas sobre los derechos de las minorías desde una perspectiva liberal son las aquí citadas.
} 
plantea que estamos encarando una nueva constelación en la gramática de los reclamos políticos que tienen dos ejes:

el primero, que se mueve de la redistribución hacia el reconocimiento y que se da en el momento de la aceleración de la globalización económica en el que la expansión del capitalismo exacerba radicalmente la desigualdad económica, a esto lo denomino el problema del desplazamiento. El segundo eje se refiere a que las luchas por el reconocimiento pueden servir no para promover la interacción respetuosa entre culturas, sino para incrementar los contextos culturales, pero simplificando y reificando drásticamente las identidades de los diferentes grupos reforzando así el separatismo, la intolerancia, el chauvinismo, el patriarcalismo y el autoritarismo, a este problema lo denomino el de la reificación. Ambos problemas, desplazamiento y reificación, son extremadamente serios. Lejos de que la política del reconocimiento desplace las políticas redistributivas puede promover la desigualdad económica. Más allá de que se reifiquen las identidades de grupo, se corre el riesgo de que se presenten violaciones a los derechos humanos (Fraser, 2000: 108).

La autora no deja de reconocer que la cultura es un legítimo y necesario terreno de lucha en el que se manifiestan injusticias pero, afirma, están profundamente imbricadas con la desigualdad económica; en ese sentido, propone tratar el reconocimiento como una cuestión de estatus social (2000: 110-113). Desde esta perspectiva, lo que requiere reconocimiento no es una identidad de un grupo específico, sino el estatus de un miembro individual del grupo para interactuar socialmente en igualdad de condiciones. El no reconocimiento no significa la depreciación o deformación de la identidad de un grupo, sino la subordinación social en el sentido de que se le niega la participación de par a par en la vida social. Además, Fraser sostiene como tesis central que la justicia social requiere tanto del reconocimiento, como de la distribución (2003). Así, discute sobre la doble dimensión de la justicia social y señala que

cada dimensión, reconocimiento y distribución, está asociada analíticamente con una forma distinta de injusticia. La dimensión del reconocimiento se asocia con el no reconocimiento. La dimensión distributiva se corresponde con la no distribución. Cada dimensión, finalmente, corresponde analíticamente a una forma distinta de subordinación: la dimensión del reconocimiento corresponde al estatus de subordinación cuya raíz está en los patrones de valores culturales institucionalizados; y la dimensión distributiva corresponde a la subordinación económica, cuya raíz se encuentra en las características estructurales del sistema económico (Fraser, 2000: 117). 
Así, la bidimensionalidad se observa en la dimensión del reconocimiento y en la de la distribución, a las que se corresponden dos formas distintas de subordinación, la cultural y la económica. Desde este enfoque, Fraser (2003) desarrolla la idea de la interseccionalidad entre diferentes categorías como raza, clase, género y etnia. ${ }^{4} \mathrm{Re}-$ fiere, por ejemplo, que la categoría de género está fluctuando entre las dos dimensiones de la injusticia social: reconocimiento y distribución.

En Canadá, uno de los grupos más vulnerables son las mujeres indígenas. En este grupo se puede observar un cruce entre género, clase y origen étnico. Por ello, es importante retomar a modo de ejemplo la situación de estas mujeres, particularmente en zonas urbanas. El interés de retomar su caso, su vulnerabilidad, porque son quienes están más expuestas a situaciones de marginación, racismo, exclusión y violencia, se debe a que a partir de su análisis es posible observar el planteamiento sobre la bidimensionalidad que traza Nancy Fraser (2000; 2003), es decir, su argumentación sobre el reconocimiento y la redistribución. De ahí se parte para presentar propuestas que consideren no sólo el tema de la cultura y el reconocimiento y acomodo de la diferencia cultural como lo propone el multiculturalismo, sino que también se aboquen a sopesar las causas estructurales de las condiciones de vida en particular de las mujeres indígenas y, en general, de los pueblos indígenas en Canadá.

\section{LOS PUEBLOS INDÍGENAS EN ZONAS URBANAS:} UNA APROXIMACIÓN DESCRIPTIVA

Si bien el Informe sobre Multiculturalismo en Canadá (Kymlicka, 2010) expone el problema del crecimiento de la población de pueblos originarios en zonas urbanas, no explica este crecimiento, ni elabora un análisis sobre las causas y previsibles consecuencias en relación con las políticas multiculturales. Es claro que no es el objetivo del Informe, pues sólo presenta un estado de cosas sobre el multiculturalismo en Canadá ${ }^{5}$ y hace una propuesta sobre las áreas en las que se debe investigar y trabajar para mejorar. Por ello, inicio haciendo una presentación de la condición actual de

\footnotetext{
${ }^{4}$ Fraser (2000: 117) acota que usa "el término 'clase' siguiendo la concepción de Max Weber". Señala que entiende "la posición de clase en tanto su relación con el mercado, no en términos de su relación con los medios de producción. Esta concepción weberiana de la noción de clase como categoría económica encaja mejor que una concepción marxista de clase como categoría social en mi interés, [...] sobre la distribución como una dimensión normativa de la justicia". Aclara que "ello no significa que rechace la idea marxista del modo capitalista de producción como totalidad social".

${ }^{5}$ Cuando hago alusión al multiculturalismo en Canadá me refiero al hecho multicultural, es decir, al multiculturalismo como dato objetivo y también aludo a las políticas multiculturales institucionalizadas por el Estado canadiense.
} 
los pueblos originarios en zonas urbanas. Hago una descripción de las causas del incremento demográfico de estas poblaciones, expongo las problemáticas más visibles que enfrentan y muestro algunos datos estadísticos sobre el crecimiento de este grupo. Pero, antes de desarrollar este primer planteamiento es pertinente hacer dos aclaraciones.

En primer término, es necesario señalar que los pueblos indígenas en Canadá no son homogéneos, hay diferencias y especificidades entre ellos. Por ejemplo, y como veremos en lo siguiente, los inuit no serán incluidos en el fenómeno de crecimiento de población aborigen en zonas urbanas, pues según los datos disponibles son muy pocos inuit los que viven en las grandes urbes, no así los pueblos de las Primeras Naciones y los métis.

La segunda aclaración es metodológica. Para la elaboración de este primer apartado retomé información de, principalmente, tres fuentes: 1) el Royal Report on the Comission of Aboriginal Peoples (1996), 2) el texto Not Strangers in these Parts. Urban Aboriginal People (2003), y 3) datos estadísticos de los censos de 1996, 2001, 2006, 2011 (Statistics Canada 2013a; 2012b; 2008; 2007; INAC 2006), así como datos proyectivos que dan cuenta del crecimiento poblacional de pueblos indígenas en zonas urbanas y de sus condiciones de vida. De estas fuentes hice un cruce de información para dar mayor sustento a lo aquí expuesto. Por último, cabe señalar que cuando hablo de pueblos aborígenes estoy haciendo una traducción literal de aboriginal people, denotación que se usa en la literatura en inglés y en los sitios web oficiales del gobierno canadiense para referirse a la población originaria. Esta alocución se refiere a las Primeras Naciones, que comprende entre seiscientas y seiscientas diecisiete bandas, los inuit y los métis (Justice Laws Website, 2013).

El gobierno canadiense utiliza el término banda para describir la unidad local bajo la administración del Ministerio de Asuntos Indígenas y el Desarrollo del Norte (Aboriginal Affairs and Northern Development, AAND). Estas unidades incluyen docenas de sociedades indígenas más complejas que se organizan tradicionalmente no como bandas, sino como tribus. Hay alrededor de poco más seiscientas bandas que funcionan como pequeñas municipalidades y son manejadas por un consejo elegido de acuerdo con la Ley Indígena (Indian Act). Las bandas no siempre coinciden con las agrupaciones lingüísticas y culturales de los pueblos indígenas (The Canadian Encyclopedia, 2012).

Por último, es preciso señalar, como parte de esta aclaración metodológica, que cuando hago referencia a zonas urbanas me refiero a lo que en los censos consultados se refiere a grandes ciudades, áreas metropolitanas (CMA) y pequeños centros urbanos. Se considera un área urbana en Canadá el lugar que tiene por lo menos mil habitantes y donde la densidad es no menor a cuatrocientas personas por kilómetro cuadrado. 
En el censo de 2011, se denominó a las áreas urbanas como population centre, buscando hacer hincapié en que la división de lo urbano frente a lo rural no es estricta. De acuerdo con la nueva definición se muestran tres tipos de centros de población: pequeño, de 1000 a 29999 habitantes; mediano, de 30000 a 99999 habitantes, y grande, de 100000 habitantes o más. A pesar del cambio en la terminología, la definición demográfica de un núcleo de población (population centre) permanece sin cambios en cuanto a lo que se considera un área urbana: una población de al menos 1000 personas donde la densidad es no menor a 400 personas por kilómetro cuadrado. Un núcleo de población, en los datos censales en Canadá, es un lugar poblado que cumple con las características demográficas de una zona urbana. El sitio web Statistics Canada contabilizó 942 núcleos de población en su censo de 2011; 513 de ellos se localizaron en Ontario o Quebec, las dos provincias más pobladas. Un núcleo de población no necesariamente corresponde a las fronteras de una municipalidad o de una división censual. Por el contrario, una sola municipalidad puede contener más de un núcleo de población distinto (Statistics Canada, 2012a).

\section{Información estadística sobre los pueblos indígenas en zonas urbanas en Canadá}

En 2011, los pueblos aborígenes representaban el 4.3 por ciento de la población total de Canadá, es decir, 1400685 personas. De este total, la mayoría habita en la provincia de Ontario (el 21.5 por ciento del total de la población aborigen), y en las provincias del oeste (Manitoba, Saskatchewan, Alberta y Columbia Británica). Las Primeras Naciones representan el 60.8 por ciento del total de la población indígena y el 2.6 por ciento del total de la población de Canadá; los métis el 32.3 por ciento del total de la población indígena y el 1.4 por ciento del total de la población canadiense; los inuit representan el 4.2 por ciento del total de la población indígena y el 0.2 por ciento de la población canadiense.

Winnipeg es la zona metropolitana en la que habita el mayor número de personas aborígenes con un 3.6 por ciento (25 970); Edmonton, con un 1.6 por ciento (18 210) y Vancouver con un 0.7 por ciento $(15080)$. Del total de personas registradas con estatus indígena en 2011, el 49.3 por ciento vivía en una reserva y el 50.7 por ciento no. Las provincias en las que se reportó el mayor porcentaje de personas con estatus indígena viviendo fuera de una reserva son Terranova y Labrador con el 64.9 por ciento, y Ontario con el 63 por ciento. Las personas pertenecientes a las Primeras Naciones con registro indígena que viven fuera de las reservas en núcleos urbanos se ubican principalmente en Prince Rupert, Columbia Británica, el 31.2 por ciento del total de 
la población; en Thompson, Manitoba, el 23.4 por ciento; en Príncipe Alberto, Saskatchewan, el 15.8 por ciento; en Yellowknife, Territorios del Noroeste, el 13.1 por ciento (aquí hay que considerar que sólo hay dos reservas, razón por la que el mayor número de personas de las Primeras Naciones vive en un núcleo urbano), y en Terrace, Columbia Británica, el 12.9 por ciento.

Los censos de las áreas metropolitanas con el mayor número de personas de las Primeras Naciones sin registro indígena mostraron los siguientes datos: Toronto, el 0.3 por ciento del total de la población; Vancouver, el 0.6 por ciento; Montreal, el 0.3 por ciento y Ottawa, el 0.7 por ciento. En el documento de consulta se hace la acotación de que en 2011, el 37.6 por ciento de las personas pertenecientes a las Primeras Naciones vivía en reservas y el 62.4 por ciento vivía fuera de ellas. De los que vivían en reservas, la vasta mayoría (98 por ciento) tenía registro indígena; de la población de Primeras Naciones que vivía fuera de las reservas, el 60.8 por ciento estaba registrado como indígena y el 39.2 por ciento no tenía registro.

En relación con los métis, el 84.9 por ciento vive en Ontario o en las provincias occidentales. La mayoría de la población se ubica en Alberta. Una cuarta parte de los métis en Canadá vive en las áreas metropolitanas del occidente; en Winnipeg se ubica la más alta proporción de métis, cerca de 46325 personas, seguida de Edmonton, Vancouver y Calgary.

\begin{tabular}{|c|c|c|c|c|c|}
\hline \multicolumn{6}{|c|}{$\begin{array}{c}\text { POBLACIÓN INDÍGENA EN LOS DIEZ MÁS GRANDES } \\
\text { CENTROS URBANOS DE CANADÁ }\end{array}$} \\
\hline & $\begin{array}{c}\text { Población } \\
\text { total }\end{array}$ & $\begin{array}{c}\text { Pueblos } \\
\text { indigenas } \\
\%\end{array}$ & $\begin{array}{c}\text { Primeras } \\
\text { Naciones } \\
\%\end{array}$ & $\begin{array}{c}\text { Métis } \\
\%\end{array}$ & $\begin{array}{c}\text { Inuit } \\
\%\end{array}$ \\
\hline $\begin{array}{l}\text { Canadá \% } \\
\text { y total }\end{array}$ & 33476688 & $\begin{array}{c}4.3 \\
1400685\end{array}$ & 851560 & 451795 & 59445 \\
\hline 1. Toronto, Ontario & 2576025 & 0.7 & 0.5 & 0.2 & \\
\hline 2. Montreal, Quebec & 1612640 & 0.6 & 0.3 & 0.2 & \\
\hline 3. Calgary, Alberta & 1082235 & 2.7 & 1.2 & 1.4 & \\
\hline 4. Ottawa, Ontario & 867090 & 2.1 & 1.2 & 0.7 & \\
\hline 5. Edmonton, Alberta & 795675 & 5.3 & 2.4 & 2.7 & \\
\hline 6. Mississauga, Ontario & 708725 & 0.5 & 0.3 & 0.1 & \\
\hline 7. Winnipeg, Manitoba & 649995 & 11.7 & 5.9 & 6.3 & \\
\hline \multicolumn{6}{|l|}{ 8. Vancouver, Columbia } \\
\hline Británica & 590210 & 2.0 & 1.3 & 0.6 & \\
\hline 9. Brampton, Ontario & 521315 & 0.7 & 0.4 & 0.2 & \\
\hline 10. Hamilton, Ontario & 509640 & 2.0 & 1.6 & 0.3 & \\
\hline
\end{tabular}


En la tabla se observa el total de la población en Canadá y en los diez centros urbanos más poblados. La ciudad de Winnipeg en la provincia de Manitoba es la que tiene el más alto porcentaje de población indígena, tanto de Primeras Naciones como de métis; sin embargo, Ontario es la provincia en la que habita el mayor número de personas perteneciente a las Primeras Naciones y el 70 por ciento vive fuera de una reserva. Los métis son los más urbanizados, en 2006 siete de cada diez vivían en zonas urbanas. No hay un registro para los inuit, pues viven en los territorios del norte, específicamente en Nunavut.

De acuerdo con datos proyectivos, hacia el año 2031 la población de las reservas aumentará, lo cual obedece esencialmente a que la población indígena es la que presenta los más altos índices de natalidad. Este crecimiento de población en las reservas no significa que la población indígena en zonas urbanas disminuya. El fenómeno de urbanización de los indígenas, en particular los miembros de las Primeras Naciones que emigran de las reservas a zonas urbanas, es progresivo y según lo que se pudo observar en los datos estadísticos, actualmente hay más personas de las Primeras Naciones viviendo en zonas urbanas que en las reservas.

El incremento de esta población, sobre todo Primeras Naciones y métis, en zonas urbanas tiene diversas aristas, no es un fenómeno unidireccional. Desde un punto de vista demográfico, el aumento de este grupo poblacional tiene que ver no sólo con un proceso natural (nacimientos), sino con la migración y con la adscripción étnica o la movilidad étnica. ${ }^{6}$ Siggner (2003: 21) explica que en los censos los pueblos indígenas se identifican con las siguientes adscripciones: “1) aboriginal origin 2) aboriginal identity, North America Indian 3) Métis 4) Inuit 5) registered Indian 6) First Nation/Band Membership". También se pueden encontrar múltiples identidades indígenas registradas en la Ley Indígena o miembros de bandas sin identidad aborigen. Siggner (2003) señala que el crecimiento en los índices de población indígena en zonas urbanas tiene relación directa con la movilidad étnica. Asimismo, Norris (2003: 63) establece que los factores que inciden en el crecimiento de las poblaciones originarias en centros urbanos son "la fertilidad, el crecimiento natural de las poblaciones, cambios legales que incluyen restituciones legislativas y estatus hereditario bajo la Ley Indígena, identificación étnica o movilidad étnica, matrimonios mixtos y formación de familias".

\footnotetext{
${ }^{6}$ La movilidad étnica es "el fenómeno por el cual individuos y familias cambian su filiación étnica" [...]. La movilidad étnica tiene dos componentes: intrageneracional e intergeneracional [...]. La movilidad intrageneracional resulta de un cambio en el tiempo, en la filiación étnica de un individuo. Por ejemplo, una persona que señale no tener identidad aborigen en un censo, pero en el siguiente censo indique tener una identidad métis, se considera que ha experimentado movilidad étnica intrageneracional [...]. La movilidad intergeneracional resulta de un cambio en la filiación étnica entre padres e hijos. Esta movilidad no implica ningún cambio en el grupo étnico para un individuo y se basa en comparar la identidad étnica de un individuo con la de sus padres (Statistics Canada, 2012c).
} 
La migración no es la única causa del crecimiento de población originaria en zonas urbanas, pero tampoco la fertilidad. Así, podemos enumerar por lo menos cinco causas en los datos estadísticos: 1) movilidad étnica, 2) cambios en la legislación, por ejemplo en la Ley Indígena (Bill C-31), 3) migración de zonas rurales (reservas) a centros urbanos o de un centro urbano a otro, 4) la tasa de natalidad entre los pueblos originarios es mayor que entre el resto de los canadienses, y 5) la urbanización hacia las reservas y zonas rurales, es decir, la expansión de las grandes urbes ha traído consigo la urbanización forzada de las reservas.

En relación con los cambios en la legislación, segundo inciso del párrafo anterior, cabe decir que la Ley Indígena es el documento que otorga reconocimiento oficial y legal a los indígenas en Canadá. Es decir, las personas que tienen un registro o estatus de indígenas lo obtuvieron siguiendo las disposiciones de la Ley Indígena. La enmienda C-31 (Bill C-31), aprobada por el Parlamento Canadiense en 1985, redefinía quién era indígena y quién no. El documento definió cuatro tipos de indígenas: 1) con estatus y por ser miembro de una banda, 2) con estatus sin membresía a una banda, 3) sin estatus, pero con membresía a una banda, 4) sin estatus y sin ser parte de una banda. A partir de esta nueva legislación, a muchas mujeres y a sus hijos se les restituyó su estatus como indígenas (Frideres, 1993).

Tras exponer descriptivamente las variables que explican el crecimiento de la población de los pueblos indígenas en zonas urbanas y dar cuenta con datos duros de ese incremento, es importante señalar cuáles son las condiciones de vida a las que se enfrentan estos pueblos en las zonas urbanas. Así, en la siguiente sección elaboro un panorama general de estas condiciones y me centro en el caso de las mujeres.

La razón por la que retomaré el caso específico de las mujeres es para reflexionar sobre el debate que abren los planteamientos de Kymlicka en el Informe sobre el Multiculturalismo en Canadá, centrado en señalar los retos del multiculturalismo de cara al crecimiento de la población indígena en zonas urbanas, retos que rebasan las políticas multiculturales que no dan cuenta de las diferencias estructurales, ni de las relaciones de subordinación política y económica, o de la intersección entre género, clase, etnia y raza.

\section{Condiciones de vida de los pueblos indígenas en zonas urbanas}

En general, la situación de los pueblos originarios en zonas urbanas es compleja y heterogénea. Las comunidades que se asientan en estas zonas siguen manteniendo un fuerte lazo con sus comunidades de origen y hacen grandes esfuerzos por reproducir su vida cultural y por mantener su identidad en los lugares de acogida. Pero 
también se da el caso en el que ese lazo no se mantiene, lo que produce una sensación de pérdida entre los individuos.

El fenómeno de urbanización de los pueblos indígenas no es nuevo, se sabe que desde la década de los años sesenta del siglo xx comenzó un proceso progresivo de crecimiento de la población aborigen en grandes centros urbanos. En ese momento, los estudios sobre este fenómeno tuvieron como eje la migración interna (Frideres, 1993: 257-280). A continuación presentaré las condiciones de vida que enfrentan. Uno de los problemas más dramáticos tiene que ver con la identidad. Según el Report of the Royal Commission on Aboriginal Peoples (RCAP) de 1996 (INAC, 2006), los temas críticos son:

1) Los retos relacionados con el sostenimiento de su identidad cultural. Ésta es el corazón mismo de su existencia y de sus demandas históricas. Se centra en la vida familiar y ceremonial, en los valores y tradiciones, en la importancia que tienen los ancianos para dar continuidad a dicha identidad, la espiritualidad, la lengua, la cosmovisión, la relación con la tierra y con los territorios ancestrales.

2) Exclusión de oportunidades para ejercer el derecho a la libre autodeterminación. El tema del autogobierno se vuelve difícil de tratar, en tanto que en las zonas urbanas tiende a manifestarse una dispersión de los miembros de las diversas comunidades.

3) Discriminación y racismo. El racismo es sistémico, se manifiestan diversas actitudes negativas y estereotipadas sobre los indígenas, hay una creciente alienación en los lugares de trabajo, por ejemplo. Otra manifestación de racismo es la idea generalizada de que ser indígena y ser urbano es mutuamente excluyente, y prevalece el corolario de que, una vez que el pueblo migra a las zonas urbanas, su identidad como indígena se vuelve irrelevante.

4) Dificultad para encontrar servicios culturalmente apropiados.

5) Desempleo, bajo nivel educativo y altos índices de pobreza, condición que es más precaria entre las mujeres.

Cabe señalar que uno de los problemas centrales en el tema de la urbanización, tanto para las autoridades no aborígenes como para las que sí lo son, tiene que ver con el autogobierno (Newhouse y Peters, 2003). Este tema, como también lo señala el Departamento de Asuntos Indígenas y Desarrollo del Norte (INAC, por sus siglas en inglés), implica cuestiones prácticas y conceptuales difíciles de resolver, sobre todo porque tiene su fundamento en la posesión territorial (INAC, 2006; The Canadian Encyclopedia, 2012c; Aboriginal Affairs and Northern Development Canada, 2012b). El 
fundamento del derecho de autogobierno se centra en los reclamos de la tierra y en la posesión de ésta; así, este derecho se "ejerce" en las reservas, por ejemplo, o en los territorios del norte en donde habitan los inuit.

Es preciso mencionar, aunque sea a grandes rasgos, a qué se refiere el tema del autogobierno para entender por qué es problemático el crecimiento de la población aborigen en zonas urbanas, específicamente de las Primeras Naciones, que son las que demandan el derecho a autogobernarse y sobre la posesión de la tierra. Aboriginal Affairs and Northern Development Canada (AANDC) señala que los acuerdos de autogobierno

establecen arreglos para que los pueblos aborígenes puedan gobernar sus asuntos internos y asumir una mayor responsabilidad y control sobre la toma de decisiones que afectan a sus comunidades. Los acuerdos de autogobierno buscan la estructura y la rendición de cuentas de los gobiernos indígenas, su poder legislativo, disposiciones financieras y sus responsabilidades para ofrecer programas y servicios a sus miembros. El autogobierno permite a los gobiernos aborígenes trabajar en colaboración con otros gobiernos y el sector privado para promover el desarrollo económico y mejorar las condiciones sociales de sus comunidades. Dado que los grupos aborígenes tienen diferentes necesidades, las negociaciones no darán lugar a un único modelo de autogobierno. El gobierno autónomo puede adoptar muchas formas con base en las diversas circunstancias históricas, culturales, políticas y económicas de los grupos indígenas, las regiones y las comunidades involucradas (AANDC, 2012b).

La cuestión del autogobierno se vuelve, pues, problemática con el crecimiento de la población indígena en zonas urbanas, en tanto que el ejercicio de este derecho tiene relación directa con la comunidad o reserva, así como los reclamos de tierras, por ejemplo.

Por otro lado, y como también lo menciona la INAC, la situación de las mujeres que se autoidentifican como miembros de las Primeras Naciones y que han migrado de las reservas en zonas rurales a zonas urbanas es más preocupante y dramática. Desde 1996, el Royal Report on the Commission of Aboriginal Peoples informaba que era mayor el número de mujeres que migraban de las reservas a zonas urbanas en relación con los hombres. En ese grupo poblacional persistía el desempleo, un bajo nivel educativo y altos índices de pobreza, y señaló contundentemente:

las mujeres que habitan fuera de las reservas con frecuencia son una minoría olvidada [...] Las mujeres aborígenes en zonas urbanas son víctimas de discriminación y segregación. Algunas [...] lo hacen para abandonar su hogar en las comunidades, escapando del 
abuso sexual y físico. Con ello se establece que no necesariamente son factores económicos los que las obligan a salir de su lugar de residencia hacia zonas urbanas. Prevalece el desempleo y con frecuencia se sienten alienadas, solas, desamparadas, desempoderadas y sin voz. El sentir general es de miedo y desconfianza, pero a pesar del hecho de vivir en un centro urbano, afirman que ello no implica que rechacen sus valores y cultura aborigen. En términos de pobreza, la situación de las mujeres es más seria, sobre todo las que son madres solteras: entre el 80 y el 90 por ciento están por debajo de la línea de pobreza (INAC, 2006).

En general, las condiciones de vida de las mujeres indígenas, es decir, de las mujeres que se identifican con una de las tres identidades indígenas en Canadá como métis, Primeras Naciones e inuit, son las más precarias y vulnerables, ya sea que habiten en zonas rurales, urbanas o en las reservas. Así, tenemos que, de todos los grupos sociales y poblacionales en Canadá, éste es el más vulnerable, expuesto a la marginación y la exclusión económica y social.

\section{Mujeres indígenas en Canadá y sus condiciones de vida, con énfasis en las zonas urbanas}

De acuerdo con el reporte Women in Canada 2010-2011 (Statistics Canada, 2011b), la población femenina indígena crece más rápido que el resto de la población femenina de ese país. De 1996 a 2006, el número creció en un 45 por ciento, mientras la población femenina no indígena tuvo un 9 por ciento de crecimiento. Según los últimos datos estadísticos de que se dispone, en 2006, el3.8 por ciento de la población femenina, es decir 600700 mujeres, reportó tener una identidad indígena. De acuerdo con datos proyectivos, hacia 2017 podría haber 717000 mujeres con este tipo de identidad (Milan y Covadonga, 2012).

En 2006, las mujeres de las Primeras Naciones representaban el 60 por ciento, las métis el 33 por ciento y las inuit el 4.2 por ciento del total de la población indígena. En ese mismo año, fuera de las reservas había un total de 174760 mujeres de las Primeras Naciones (hay que tener en cuenta que los miembros de éstas generalmente habitan en las reservas, los métis en su mayoría se ubican en zonas rurales y urbanas de la provincia de Alberta y los inuit en los territorios del norte y principalmente en zonas rurales). Así, en 2006 más de la mitad, el 55 por ciento de mujeres aborígenes vivía en un área metropolitana, el 25 por ciento en reservas y el 20 por ciento en zonas rurales (Milan y Covadonga, 2012).

Manitoba y Saskatchewan son las provincias con mayor proporción de mujeres indígenas y Ontario es la provincia en la que habita el mayor número de niñas y mu- 
jeres de las Primeras Naciones. Winnipeg, Saskatoon y Regina son los centros urbanos con mayor concentración de mujeres indígenas. Estos datos indican que más de la mitad de mujeres de las Primeras Naciones (que además es la proporción más alta de población de pueblos aborígenes) vive en zonas urbanas.

En cuanto a los índices económicos, según la información presentada en los informes Women in Canada 2010-2011 y Aboriginal Women in the Canadian Economy (AANDC, 2012a), las mujeres aborígenes tienen un menor ingreso, un menor nivel de empleos y les es más difícil insertarse en el mercado laboral que a las mujeres de otro origen y que a los hombres aborígenes. Las indígenas en las reservas estan particularmente marginadas; el 71 por ciento de ellas que tiene educación posterior a la secundaria encuentra empleo. Según los datos de 2006, la tasa de mujeres indígenas desempleadas alcanzaba un 13.5 por ciento y la de mujeres no indígenas el 6.4 por ciento, es decir, tienen el doble de desempleo. Es un índice muy elevado si tomamos en cuenta que las mujeres aborígenes sólo representan el 4 por ciento de la población total de Canadá.

Otros datos sobre la educación y los niveles de ingreso indican que el 35 por ciento de las mujeres indígenas de 25 años y más se habían graduado en la educación media superior (high school), y que una de cada cinco, el 23 por ciento, entre los 15 y los 34 años de edad había abandonado los estudios por embarazo o por dedicarse al cuidado de los niños. El 9 por ciento de mujeres indígenas de más de 25 años obtuvieron un grado universitario, un porcentaje muy bajo comparado con el 20 por ciento de las mujeres no aborígenes que lo tienen. En ese sentido, y según lo que los informes de referencia indican, hay un claro lazo entre nivel de educación e ingresos; por lo tanto, las indígenas tienen un menor nivel de ingreso comparado no sólo con las mujeres de otros orígenes, sino también con los hombres indígenas.

\section{Exposición a la violencia}

De acuerdo con el documento Violent Victimization of Aboriginal Women in the Canadian Provinces, 2009: “en 2009, cerca de sesenta y siete mil mujeres aborígenes de más de quince años reportaron ser víctimas de la violencia". Este dato indica que "las mujeres aborígenes están tres veces más expuestas a situaciones de violencia que las mujeres no aborígenes". Al mismo tiempo, señala que "entre las víctimas de violencia doméstica, cerca de seis de cada diez mujeres aborígenes informaron que fueron lastimadas durante los cinco años previos a la encuesta, en comparación con cuatro de cada diez mujeres no aborígenes" (Shannon, 2011). Los abusos de los que son víctimas pueden ser de tipo emocional, físico o económico. Los datos muestran que ellas tienen una mayor exposición y vulnerabilidad a ser víctimas de la violencia doméstica 
y, según datos estadísticos de 2011, la violencia doméstica y sexual es 3.5 veces más alta que entre otras mujeres.

Sin embargo, la violencia doméstica no es la única situación de victimización a la que se enfrentan las indígenas en Canadá. Muchos informes y de muy diversa índole, por parte de organizaciones de derechos humanos como Amnistía Internacional, Human Rights Watch u organizaciones de mujeres indígenas de Canadá, como Sister Watch Project y Sisters in Spirit, han documentado las desapariciones y homicidios de mujeres indígenas.

Los informes citados coinciden en señalar que las mujeres aborígenes de entre 25 y 44 años son cinco veces más propensas a morir de manera violenta que otras mujeres. Las mujeres aborígenes representan el 4 por cierto de la población femenina en Canadá, pero son el grupo poblacional sobre el que se informa un mayor número de mujeres desaparecidas y asesinadas. Según la información recopilada por Native Women's Association of Canada (NWAC), hay 582 casos conocidos de mujeres desaparecidas o asesinadas, la mayoría de los cuales ocurrieron entre 1990 y 2010. Amnistía Internacional informó también en 2012 que cinco mujeres indígenas de cada siete mujeres en Canadá han muerto como resultado de la violencia (NWAC, 2010).

De acuerdo con el reporte del Missing Women Working Group 2006, en Canadá las mujeres más vulnerables para ser víctimas de predadores sexuales tenían las siguientes características: ser indígenas, ser pobres, no tener casa ni apoyo de redes sociales, ser adictas a las drogas o el alcohol, verse involucradas en la prostitución u otras actividades peligrosas, como viajar pidiendo "aventón", o padecer algún tipo de desorden mental. Estas características coinciden en todos los informes elaborados por otras organizaciones de derechos humanos. Asimismo, el reporte de 2010 del Grupo de Trabajo Federal/Provincial y Territorial señalaba que las mujeres ingresan al mercado sexual por dos razones esencialmente: por necesidad económica y por adicción a las drogas. Por ejemplo, señala el informe, en Vancouver durante 2004, se hizo un estudio con 183 mujeres que se dedicaban a la prostitución: de ellas, el 30 por ciento eran indígenas y, de ese porcentaje, un 65 por ciento había iniciado esa actividad por necesidad económica y/o por algún tipo de adicción.

El informe de Amnistía Internacional titulado Stolen Sisters. A Human Rights Response to Discrimination and Violence against Indigenous Women in Canada (2004) indica que

los factores que en Canadá han llevado a que permanezca el riesgo de las mujeres indígenas de ser víctimas de la violencia en las ciudades canadienses son la marginación social y económica, y el racismo que se enraíza en el pasado colonial [...] para estas mujeres, frecuentemente la violencia ocurre en un contexto determinado por el poder de la sociedad 
dominante y que fue ejercido sobre cada aspecto de la vida de los pueblos aborígenes, desde la forma en que fueron educados, la forma en que podían ganarse la vida, hasta la forma en que fueron gobernados.

Históricamente, en la mayoría de las culturas indígenas que hoy son parte de Canadá, continúa Amnistía Internacional,

existieron roles de género para hombres y mujeres que los mantenían en una situación de relativa igualdad entre sí. Debido a la implantación de políticas impuestas sin su consentimiento, los pueblos aborígenes en Canadá tuvieron que lidiar con la pérdida de sus territorios, la disociación de sus roles y responsabilidades tradicionales, en su participación en las decisiones políticas y sociales en sus comunidades y la posibilidad de renunciar a su cultura y tradiciones. El colonialismo dejó un profundo y negativo impacto en las comunidades indígenas que también afectó las relaciones entre las mujeres y los hombres, y obligó a muchas mujeres aborígenes a permanecer marginadas de sus propias culturas y de la sociedad canadiense (IA, 2013: 8; Bourgeault, 1991; Ponting, 1998; Naumann, 2008; The Canadian Encyclopedia, 2012d).

En ese mismo sentido, el reporte de la NWAC indica que de acuerdo con sus propias investigaciones han encontrado que "hay un impacto intergeneracional y de vulnerabilidad como resultado directo de la colonización y de las políticas estatales, como las escuelas residenciales, the sixties scoop ${ }^{7}$ y el sistema de cuidado infantil, todos éstos, factores que subyacen a la situación de violencia a la que son expuestas las mujeres y niñas aborígenes".

Aunado a la herencia colonial, el reporte señala que de acuerdo con la investigación realizada, también "se identifican ciertas características sociodemográficas asociadas a los altos índices de violencia contra las mujeres". Tales características no pueden ser consideradas la causa de la violencia,

pero son factores que ayudan a identificar el contexto en el que la violencia ocurre. Así, estos factores que han sido frecuentemente encontrados en diversos análisis son: 1) la

\footnotetext{
${ }^{7}$ El llamado sixties scoop se refiere a la adopción en Canadá de niños indígenas, sobre todo de las Primeras Naciones y métis, durante la década de los años sesenta y mediados de los ochenta. Se le denomina así por el alto índice de adopciones que se dio en aquella época y porque en muchos casos los niños literalmente fueron arrebatados de sus casas y comunidades sin el conocimiento o consentimiento de sus familias. Miembros de las Primeras Naciones señalaron que, en muchos casos en los que no se dio el consentimiento para la adopción, las autoridades gubernamentales y los trabajadores sociales actuaron bajo la presunción colonialista de que los pueblos indígenas eran culturalmente inferiores y que, por tanto, estaban actuando para proveer a los niños de lo que necesitaran (NWAC, 2010).
} 
edad; los índices de violencia son más altos entre las mujeres jóvenes; 2) el abuso físico y emocional en la familia progenitora está determinado como uno de los indicadores de que la mujer que crece en un hogar con estas características podría ser víctima de abuso físico y sexual en las relaciones maritales; 3 ) factores socioeconómicos, tales como bajos ingresos, desempleo o bajo nivel educativo; 4) abuso de alcohol. Otros factores son ser miembro de una familia con un solo progenitor, vivir en condiciones de hacinamiento, una familia muy grande, haber tenido un matrimonio anterior, altos índices de movilidad residencial, haber experimentado abuso sexual y adicción a las drogas.

Por su parte, el informe de Human Rights Watch (HRW, 2013) Those Who Take Us Away: Abusive Policing and Failures in Protection of Indigenous Women and Girls in Northern British Columbia, Canada también evidencia la responsabilidad del Estado y de las fuerzas policiacas en la no pronta y ni expedita respuesta en la resolución de las desapariciones y homicidios de mujeres aborígenes. A la par del reporte de IA, HRW informa sobre "los malos tratos marcados por actitudes racistas y sexistas por parte de la policía en el momento en que los familiares denuncian desapariciones de mujeres".

Según se demuestra siguiendo diferentes fuentes como estos dos informes, el Report of the Royal Comission on Aboriginal Peoples y el Informe sobre el Multiculturalismo, punto de partida de este trabajo, entre otros, se puede afirmar que los pueblos indígenas en zonas urbanas se encuentran con diversos obstáculos, entre los que destacan el aislamiento social y la pérdida de su identidad. Asimismo, Carole Lévesque señala que uno de los problemas que con frecuencia van a enfrentar tiene que ver con los bajos niveles de educación y la falta de experiencia laboral, lo cual limita su acceso al mercado de trabajo o los relega a trabajos precarios (Lévesque, 2003: 27). Así, reitera Norris: "el aislamiento social y la marginación económica tienen implicaciones en el incremento de la movilidad y en las necesidades y retos que encaran los pueblos aborígenes para establecer sus propias instituciones y desarrollar la cohesión social dentro del contexto urbano" (Norris, 2003: 72).

Así, el racismo que, como se observó en los reportes de IA, HRW y NWAC, está anclado al pasado colonial y a las políticas de asimilación; junto con la exclusión, la pérdida de la identidad cultural, la marginación, el poco o nulo acceso a servicios de salud, educación y vivienda, la pobreza, las adicciones y el desempleo son algunos de los problemas más acuciantes que enfrentan las personas pertenecientes a pueblos aborígenes, en general, y en particular los que viven en zonas urbanas. ${ }^{8}$ Las

\footnotetext{
${ }^{8}$ Éstas son algunas fuentes que daban cuenta de la situación de pobreza, marginación social y económica, bajo nivel educativo y desempleo: World Directory of Minorities and Indigenous Peoples, 2005; The Canadian Encyclopedia, 2012a y 2012b. Es interesante también que Amnistía Internacional tiene una sección dedicada a los problemas más acuciantes que aquejan a los pueblos indígenas en Canadá como la discriminación,
} 
causas de los problemas que encaran estos pueblos son de orden estructural, hay una superposición entre su condición de pueblos indígenas, género y clase. Lo anterior se observa, sobre todo, en las condiciones de vida de las mujeres aborígenes, donde destaca su vulnerabilidad ante la violencia sexista y racista. ${ }^{9}$

\section{REFLEXIÓN FINAL Y CONCLUSIONES}

De las tesis de Fraser $(2000 ; 2003)$ se infiere que en el caso de los pueblos indígenas en zonas urbanas (caso específico de las mujeres), es manifiesta una relación de subordinación con respecto al resto de la sociedad canadiense. Revisando, por ejemplo, los casos documentados por organizaciones como IA y HRW sobre la violencia a la que se ven expuestas las mujeres indígenas, podemos establecer que hay patrones institucionalizados de valores culturales que refuerzan el racismo y los estereotipos en contra de estas mujeres por su condición de indígenas, de mujeres y de marginación económica y social al tener que ejercer la prostitución como medio de subsistencia.

El problema de la distribución afecta directamente a las mujeres indígenas porque tienen pocas o nulas oportunidades de encontrar empleos bien remunerados a causa de su escasa formación técnica y / o académica que impacte de manera benéfica en su vida a la hora de establecerse en una zona urbana. Con frecuencia, estas mujeres se enfrentan la necesidad de ejercer la prostitución con las consecuencias que esa práctica conlleva, como la vulnerabilidad frente a la violencia, contagio de $\mathrm{VIH}$, adicciones, etc. El problema de la distribución también las afecta directamente en tanto que muchas de ellas son madres solteras; y viviendo fuera de las reservas, con frecuencia se encuentran con numerosas dificultades para otorgar los servicios necesarios de salud, educación, vivienda, etc., a sus hijos.

Este empalme de múltiples identidades y condiciones de subordinación es escasa o nulamente analizado por las teorías multiculturales que centran sus estudios en el acomodo y reconocimiento cultural, sin dar cuenta de la condición de clase o de la jerarquización patriarcal al interior de las comunidades, por ejemplo, o del desempoderamiento y subordinación, y que no se explican sólo por la falta de reconocimiento de la identidad cultural diferenciada.

\footnotetext{
el acceso limpio y seguro al agua, la violencia contra las mujeres, los reclamos relacionados con el autogobierno y la posesión de las tierras (IA, 2012).

${ }^{9}$ El racismo, la marginación y la pobreza que permea entre la población indígena en Canadá sigue tan vigente que en el año 2014 el relator especial de las Naciones Unidas sobre los derechos de los pueblos indígenas, James Anaya, entregará un reporte sobre su visita a Canadá. Los principales problemas tienen que ver con el acceso al agua potable, educación y vivienda, entre otros (El Semanario, 2013; ABC, 2013). Sobre el racismo en Canadá, específicamente el que involucra a los pueblos aborígenes, véase Ponting, 1998.
} 
Si bien es cierto que el multiculturalismo como política de acomodo y reconocimiento en Canadá no fue pensado para dar solución a las demandas de los pueblos indígenas, hoy día estas políticas multiculturales enfrentan el difícil reto del crecimiento de población en zonas urbanas. Y es justo en el análisis de las condiciones de vida a las que se enfrentan estos pueblos, y específicamente las mujeres, que podemos hacer una crítica al multiculturalismo que se centra en el reconocimiento, pero, paradójicamente, sin reconocer la interseccionalidad de la que nos habla Fraser (2000; 2003), ni la subordinación cultural, económica y política.

Es así que, reitero, las políticas multiculturales por sí solas difícilmente resolverán la situación que enfrentan las mujeres indígenas en Canadá, situación que se enraíza al pasado colonial, ${ }^{10}$ en el que, por medio de diversas políticas de asimilación, como las escuelas residenciales, entre otras, las familias fueron separadas y las formas tradicionales de vida de los pueblos aborígenes, interrumpidas. Considero necesario reflexionar sobre la violencia estructural que subyace a la situación de vida que enfrentan estos pueblos, particularmente las mujeres. Sin esa reflexión no creo posible que el Estado canadiense pueda avanzar en el tema de los derechos de estos pueblos.

Aun cuando, inserto en la tradición democrático-liberal y de defensa de los derechos humanos y de la diversidad, el Estado canadiense ha tenido la mejor intención de querer subsanar las diversas desventajas políticas, económicas y sociales que enfrentan los pueblos aborígenes, haciendo uso de políticas e instrumentos jurídicos como la Ley Indígena (Bill C-31), la Constitución de 1982 (Bill C-35) que incluye la Carta de Derechos y Libertades, así como el trabajo realizado por la Royal Commission on Aboriginal Peoples que, desde 1996, hizo recomendaciones sobre las que se debía trabajar, o el AAND, entre otras instancias, parece que la voluntad y los buenos deseos no son suficientes para dar solución a la situación que viven estos pueblos que, cabe decir, también están organizados políticamente dentro de sus comunidades.

Así, para alcanzar la justicia social en favor de los pueblos aborígenes de Canadá, en general, es preciso no sólo reconocer su identidad cultural diferenciada, sino entender que la causa de sus condiciones de vida actual se enraiza en el colonialismo al que fueron sujetos y obedece a un orden sistémico o estructural. Por lo tanto,

1) Las condiciones de marginación, pobreza, exclusión, racismo, sexismo, etc. a las que se ven expuestos los pueblos indígenas, pero particularmente las mu-

\footnotetext{
${ }^{10}$ El legado colonial da forma a lo que se define como patrones de valores culturales institucionalizados que han generado estereotipos sobre los pueblos aborígenes. También, esos patrones están presentes cuando se observan actitudes sexistas y racistas a las que, con frecuencia, son sujetos los pueblos indígenas en general y en particular las mujeres cuando son sometidas a acciones de violencia como asaltos sexuales y asesinatos.
} 
jeres en zonas urbanas, son consecuencia de una situación de subordinación política, social y económica.

2) La situación de violencia física a la que se ven (y se han visto) sometidas las mujeres aborígenes se explica por lo que Galtung (2004) describe como violencia estructural y cultural.

3) Siguiendo con el punto anterior, es necesario no sólo proponer políticas de reconocimiento, sino entender que el racismo, los estereotipos y el sexismo son producidos y reproducidos por "patrones de valores culturales" que han sido institucionalizados.

4) Es preciso reconocer que la cuestión de los pueblos indígenas que viven en zonas urbanas, y muy particularmente la situación de las mujeres en esta condición, no se explica ni se soluciona con la aplicación de políticas multiculturales centradas sólo en dar cuenta de la forma en que se interactúa y se relacionan las diferentes minorías en el espacio público.

Por último, cabe señalar que el tema de la violencia estructural y la violencia de género no necesariamente se resuelve con la redistribución. Pero, tomando en cuenta la idea de bidimensionalidad, es decir, reconocimiento y redistribución, los pueblos aborígenes, en general, y las mujeres aborígenes en particular, lograrán tener un mejor estándar de vida y alcanzar una mayor justicia social. Tener un mejor acceso a educación y mejores ingresos supondrá una menor exposición a situaciones de violencia.

\section{FUENTES}

\section{ABC, Agencia de Noticias}

2013 "Relator de la onu advierte que Canadá se enfrenta a 'crisis' de indígenas", en $<$ http: / / www.abc.es/ agencias / noticia.asp?noticia=1515611>, consultada en octubre de 2013 .

Aboriginal Affairs and Northern Development Canada (aAndc)

2013 First Nations, digital 02/08/2013, en <http: / / www.aadnc-aandc.gc.ca/ eng / 1100100013791 / $1100100013795>$, consultada en mayo de 2012.

2012a Aboriginal Women in the Canadian Economy. The Links between Education, Employment and Income (PDF) QS-7117-000-EE-A1 Catalog: R3-161/2012E.

2012b "Self-Goverment", en <http: / / www.aadnc-aandc.gc.ca/eng/ 110010003227 5/1100100032276>, consultada en mayo de 2013. 


\section{Assembly of First Nations (AFN)}

s.f. A Declaration of First Nations, en <http: / / www.afn.ca/index.php/ en/aboutafn/a-declaration-of-first-nations>, consultada en septiembre de 2013.

\section{BARRY, BRIAN}

2001 Culture and Equality: An Egalitarian Critique of Multiculturalism, Cambridge, Harvard University Press.

\section{BOURGEAULT, RON}

1991 "Race, Class and Gender: Colonial Domination of Indian Women", en Ormond McKague, ed., Racism in Canada, Saskatoon, Saskatchewan Fifth House, pp. 87-115.

\section{Brassard, RenÉE y MyLÉne JacCOUd}

2003 "The Marginalization of Aboriginal Women in Montréal", en David Newhouse y Evelyn Peters, eds., Not Strangers in These Parts. Urban Aboriginal Peoples, Ottawa, Policy Research Initiative, pp. 131-145.

\section{BRENNAN, SHANON}

2011 "Violent Victimization of Aboriginal Women in the Canadian Provinces, 2009", Component of Statistics Canada catalogue No. 85-002-X, Juristat, en <http: / / www.statcan.gc.cal/ pub / 85-002-x/20011001/article / 11439-eng. htm $>$, consultada en mayo de 2012.

\section{Conferencia Mundial contra el Racismo}

2001 Doctrinas del despojo". El racismo contra los pueblos indígenas, en <http: / / www. un.org/spanish/CMCR/indigenous.htm>, consultada en octubre de 2013.

\section{Coordinating Committee of Senior Officials Missing Women Working Group} (CCSOMWWG)

2010 Report: Issues Related to the High Number of Murdered and Missing Women in Canada, en <http: / / www.scics.gc.ca/CMFiles / 830992005_e1MAJ-2112011-6827. pdf $>$, consultada en septiembre de 2013 .

\section{Díaz-Polanco, Héctor}

2006 Elogio de la diversidad. Globalización, multiculturalismo y etnofagia, México, Siglo XXI. 
Dick, Caroline y Kiera L. Ladner

2008 "Out of the Fires of Hell: Globalization as a Solution to Globalization - An Indigenist Perspective", Canadian Journal of Law and Society, vol. 23, nos. 1-2, pp. 63-91.

\section{El Semanario. Sin LÍMites}

2013 "Población autóctona canadiense golpeada por discriminación, marginación y pobreza", digital, 21 de mayo, en <http://www.elsemanario.com/noticias / internacional / 84852-poblacion-autoctona-canadiense-golpeada-pordiscriminacion-marginacion-y-pobreza.html>, consultada en mayo de 2013.

\section{FRASER, NANCY}

2003 "Social Justice in the Age of Identity Politics: Redistribution, Recognition, and Participation", en Nancy Fraser y Axel Honneth, Redistribution or Recognition?: A Political-philosophical Exchange, Londres, Verso, pp. 7-109.

2000 "Rethinking Recognition", New Left Review, no. 3, mayo-junio, pp. 107-120.

FRIDERES, JAMES S.

1993 Native Peoples in Canada. Contemporary Conflicts, Ontario, Prentice Hall Canada.

GALTUNG, JOHAN

2004 Violencia, guerra y su impacto. Sobre los efectos visibles e invisibles de la violencia, en <http:/ / them.polylog.org/5/fgj-es.htm>, consultado el 17 de mayo de 2013.

Guimond, ERIC

2003 "Fuzzy Definitions and Population Explosion: Changing Identities of Aboriginal Groups in Canada", en David Newhouse y Evelyn Peters, eds., Not Strangers in These Parts. Urban Aboriginal Peoples, pp. 35-49.

HONNETH, AXEL

1997 La lucha por el reconocimiento: por una gramática moral de los conflictos sociales, Barcelona, Grijalbo.

\section{Human Rights Watch (HRW)}

2013 Those Who Take us Away. Abusive Policing and Failures in Protection of Indigenous Women and Girls in Northern British Columbia, Canada, en <http: / www. hrw.org / reports / 2013/02/13/those-who-take-us-away-0>, consultada en abril de 2013. 
Indian And Northern Affairs Canada (INAC)

2006 Royal Report on the Comission of Aboriginal Peoples (1996). Volume 4: Perspectives and Realities. Chapter 7 Urban Perspectives. Aboriginal Women in Urban Areas, en <http: / / www.collectionscanada.gc.ca / webarchives / 20071211052246/ http:/ / www.ainc-inac.gc.ca/ch/rcap/sg/sj42_e.html>, consultada en abril de 2013.

INTERNATIONAL AMNESTY (IA)

2012 "Indigenous Peoples in Canada", en <http: / / www.amnesty.ca/ our-work/ issues / indigenous-peoples/indigenous-peoples-in-canada>, consultada el 27 de mayo de 2013.

2004 Canada Stolen Sisters. A Human Rights Response to Discrimination and Violence against Indigenous Women in Canada, en <http: / www.amnesty.org/en/library / asset / AMR20 / 001 / 2004 / en / 48f05a31-d589-11dd-bb24-1fb85fe8fa05 / amr200012004en.pdf $>$, consultada en abril de 2013 .

Justice LaWs Website

2013 Constitution Acts, 1867 to 1982. Part II Rights of the Aboriginal Peoples of Canada, en $<\mathrm{http}$ / / laws-lois.justice.gc.ca/eng/const/page-16.html\#h>, consultada en mayo de 2012.

2012 Canadian Multiculturalism Act 1985, en <http:/ / laws-lois.justice.gc.ca/eng/ acts / c-18.7 / page-1.html>, consultada en septiembre de 2013.

\section{KUKHATHAS, CHANDRAN}

2003 The Liberal Archipielago: A Theory of Diversity and Freedom, Nueva York, Oxford University Press.

KYMLICKA, WILL

2010 The Current State of Multiculturalism in Canada and Research Themes on Canadian Multiculturalism 2008-2010, Department of Citizenship and Inmigration, Goverment of Canada, en <http: / / www.cic.gc.ca/english/pdf/pub/multistate.pdf $>$, consultada en diciembre de 2012.

2007 Multicultural Odissey. Navigating the New International Politcs of Diversity.

2004 Estados, naciones y culturas, Córdoba, Almuzara.

2003 La política vernácula. Nacionalismo, multiculturalismo y ciudadanía, México, Paidós.

1996 Ciudadanía multicultural. Una teoría liberal de los derechos de las minorías, México, Paidós. 
La Prairie, Carol y Philip Stenning

2003 "Exile on Main Street: Some Thoughts on Aboriginal Over-Representation in the Criminal Justice System", en David Newhouse y Evelyn Peters, eds., Not Strangers in These Parts. Urban Aboriginal Peoples, Canadá, Policy Research Initiative, pp. 179-193.

\section{LÉvesque, CARole}

2003 "The Presence of Aboriginal Peoples in Quebec's Cities: Multiple Movements, Diverse Issues", en David Newhouse y Evelyn Peters, eds., Not Strangers in These Parts. Urban Aboriginal Peoples, Canada, Policy Research Initiative, pp. 23-34.

\section{MAHAJAN, GuRPREET}

2002 The Multicultural Path. Issues of Diversity and Discrimination in Democracy, Nueva Delhi, Sage.

Milan, Anne y Covadonga Robles

2012 Female Population, Statistics Canada en <http:/ / www.statcan.gc.ca/pub/89503-x/ 2010001 / article/ 11475-eng.htm\#a5>, consultada en septiembre de 2013.

Ministry of Justice

2012 "Missing Women Working Group", en <http://www.ag.gov.ba/missing women_working_group/index.htm>, consultada en mayo de 2013.

Native Women's Association of Canada (nWac)

2010 What Their Stories Tell Us. Research Findings from the Sisters in Spirit Initiative, en <http://www.nwac.ca/sites/default/files/reports/2010_NWAC_SIS_Report_ EN.pdf $>$, consultada en septiembre de 2013.

\section{NAUMANN, DANIELLE}

2008 "Aboriginal Women in Canada: On the Choice to Renounce or Reclaim Aboriginal Identity", Canadian Journal of Native Studies, vol. 28, no. 2, pp. 343-361.

\section{Newhouse, DAvid}

2003 "The Invisible Infraestructure: Urban Aboriginal Institutions and Organizations", en David Newhouse y Evelyn Peters, eds., Not Strangers in These Parts. Urban Aboriginal Peoples, Canada, Policy Research Initiative, pp. 243-253. 
Newhouse, David R. y Evelyn Peters

2003 "The Way Forward", en David Newhouse y Evelyn Peters, eds., Not Strangers in These Parts. Urban Aboriginal Peoples, Canada, Policy Research Initiative, pp. 281-284.

NoRRIS, MARY JANE

2003 "Aboriginal Mobility and Migration within Urban Canada: Outcomes, Factors and Implications", en David Newhouse y Evelyn Peters, eds., Not Strangers in These Parts. Urban Aboriginal Peoples, Canada, Policy Research Initiative, pp. 51-78.

PAREKH, BHIKHU

2002 Rethinking Multiculturalism: Cultural Diversity and Political Theory, Cambridge, Harvard University Press.

PONTING, Rick J.

1998 "Racism and Stereotyping of First Nations", en Vic Satzewich, ed., Racism and Social Inequality in Canada. Concepts, Controversies and Strategies of Resistance Toronto, Thompson Educational, pp. 269-298.

SHANON, BRENNAN

2011 "Violent Victimization of Aboriginal Women in the Canadian Provinces, 2009", Component of Statistics Canada Catalogue no. 85-002-X Juristat.

Siggner, ANDREW J.

2003 "Urban Aboriginal Populations: An Update Using the 2001 Census Results", en David Newhouse y Evelyn Peters, eds., Not Strangers in These Parts. Urban Aboriginal Peoples, Canada, Policy Research Initiative, 15-21.

\section{Statistics CANADA}

2013a Aboriginal Peoples in Canada: First Nations People, Métis and Inuit, en <http: / / www12.statcan.gc.ca/nhs-enm/2011/as-sa/99-011-x/99-011-x2011001-eng. cfm>, consultado en mayo de 2013.

2013b Inmigration and Etnocultural Diversity in Canada, en <http:/ / www12.statcan. gc.ca/nhs-enm/2011/as-sa/99-010-x/99-010-x2011001-eng.cfm>, consultado en mayo de 2013.

2012a From Urban Areas to Population Centres (11 de mayo), en <http:/ / www.statcan. gc.ca/ subjects-sujets / standard-norme/sgc-cgt/ notice-avis / sgc-cgt-06-eng. htm >, consultado en septiembre de 2013. 
2012b Population Projections by Aboriginal Identity in Canada, 2006 to 2031. Highlights, en <http:/ / www.statcan.gc.ca/pub/91-552-x/2011001/hl-fs-eng.htm>, consultada en mayo de 2013.

2012c Population Projections by Aboriginal Identity in Canada, 2006 to 2031. Analysis of Results, en <http://www.statcan.gc.ca/pub/91-552-x/2011001/ana-eng.htm>, consultada en marzo de 2013.

2011a Population Projections by Aboriginal Identity in Canada, 2006 to 2031. Highlights, en <http: / / www.statcan.gc.ca/pub/91-552-x/2011001/hl-fs-eng.htm>.

2011b Women in Canada: A Gender-based Statistical Report. Component of Statistics Canada Catalogue no. 89-503-X.

2008 Aboriginal People in Canada 2006: Inuit, Métis and First Nations, 2006 Census. Aboriginal Peoples, 2006 Census, Catalogue no. 97-558-XIE.

2007 Where Do Aboriginal People Live?, en <http://www41.statcan.gc.ca/2007/ 10000 / ceb10000_003-eng.htm>, consultada en mayo de 2013.

TAYLOR, CHARLES

1993 Multiculturalismo y política del reconocimiento, México, Fondo de Cultura Económica.

\section{The CANADIAN ENCYCLOPEDIA}

2012a Aboriginal People, Economic Conditions, en <http: / / www.thecanadianencyclopedia. com/articles/economic-conditions-of-native-people $>$, consultada en mayo de 2013.

2012b Aboriginal People, Social Conditions, en <http: / / www.thecanadianencyclopedia. com/articles / native-people-social-conditions $>$, consultada en abril de 2013.

2012c Aboriginal Self-Goverment, en <http:/ / www.thecanadianencyclopedia.com/ articles / aboriginal-selfgovernment>, consultada en mayo de 2013.

2012d Aboriginal Women's Issues, en <http:/ / www.thecanadianencyclopedia.com/ articles / native-womens-issues>, consultada en abril de 2013.

2012e Band, en <http:/ / www.thecanadianencyclopedia.com/articles/band>, consultada en septiembre de 2013.

TULLY, JAMES

1995 Strange Multiplicity Constitutionalism in an Age of Diversity, Cambridge, Cambridge University Press. 
World Directory of Minorities And Indigenous Peoples (wdmip)

2005 First Nations. Current Issues, en <http: / / www.minorityrights.org/2627/ canada / first-nations.html>, consultada en mayo de 2013.

ŽIŽEK, SLAVOJ

2007 En defensa de la intolerancia, Madrid, Sequitor.

1998 "Multiculturalismo, o la lógica cultural del capitalismo multinacional", en Fredric Jameson y Slavoj Žižek, Estudios culturales. Reflexiones sobre el multiculturalismo. Introducción de Eduardo Grüner. México, Paidós. 